\title{
Article
}

\section{Heart Rate Variability in Hyperthyroidism}

\author{
Kabir R $\mathbf{R}^{1}$, Begum N², Ferdousi S , Begum S $^{4}$, Ali T ${ }^{5}$
}

\begin{abstract}
Background: Hyperthyroidism is associated with altered cardiac autonomic nervous activity (CANA). Heart Rate Variability (HRV) analysis is a promising technique to quantify CANA and therefore can be done in hyperthyroidism. Objective: To observe the HRV parameters in patients with hyperthyroidism to find out the influence of excess thyroid hormone on cardiac autonomic nervous activities. Method: The cross sectional study was carried out on 60 hyperthyroid patients (groupB)aged 30-50 years in the Department of Physiology, BSMMU, Dhaka from $1^{\text {st }}$ July 2007 to $30^{\text {th }}$ June 2008. Age and sex matched 20 apparently healthy euthyroids were also studied for comparison (group A). On the basis of treatment, they were further divided into group $\mathrm{B}_{1}$ consisting of 30 untreated newly diagnosed patients and group $B_{2}$ consisting of 30 hyperthyroid patients treated with antithyroid drugs for at least 2 months. The patients were selected from the Out Patient Department of Endocrinology, BSMMU, Dhaka. To assess thyroid status, serum TSH and serum $\mathrm{FT}_{4}$ levels were measured by AxSym system and time domain measures of HRV such as mean R-R interval, mean heart rate, SDNN and RMSSD were assessed from 5minute(short term) ECG recording by a polygraph. For statistical analysis Mann-Whitney U test was done. Results: Mean R-R interval was significantly $(\mathrm{P}<0.001)$ lower but mean heart rate was significantly $(\mathrm{P}<0.001)$ higher in untreated patients than those of treated and euthyroids subjects. These values were found almost similar when compared between euthyroids and treated hyperthyroids. Similarly SDNN and RMSSD were significantly lower in untreated hyperthyroids than both euthyroids $(\mathrm{P}<0.001)$ and treated hyperthyroids $(\mathrm{P}<0.01)$. Conclusion: This study concluded that decreased vagal modulation on heart rate may occur in hyperthyroidism, which may be restored following adequate treatment of the disease.
\end{abstract}

Keywords: HRV, R-R Interval, Heart rate, RMSSD, Hyperthyrodism

J Bangladesh Soc Physiol. 2009 Dec;4(2): 51-57 For author affiliations, see end of text.

http//www.banglajol.info/index.php/JBSP

\section{Introduction}

$\mathbf{D}$ eviation from normal thyroid status has profound influence on all body systems including cardiovascular system. Changes in serum thyroid hormone levels are usually associated with alteration in autonomic regulation of cardiovascular activity. ${ }^{1,2}$

It has been reported that the parasympathetic regulatory effect on heart rate is reduced in hyperthyroid patients. ${ }^{3-6}$ Moreover, parasympathetic blocker reduces vagal activity that determines autonomic imbalance in hyperthyroidism. ${ }^{7}$

51
Several investigators reported higher sympathetic tone with impaired parasympathetic modulation and consequent tachycardia in hyperthyroid patients. 3 , 8-15

Clinical features of hyperthyroidism are similar to that of excess catecholamines but studies demonstrated lower turnover rate of catecholamines. ${ }^{16,17}$ Some investigators reported increased sympathetic activity in hyperthyroid patients with beta-receptor blocking drugs. ${ }^{2,8,18-20}$ There may be alteration of catecholamine binding and affinity for receptors in presence of thyroid hormone excess. ${ }^{20-24}$

J Bangladesh Soc Physiol. 2009 Dec;4(2): 51-57 
The thyroid hormone has direct effect on exaggeration of sinus nodal rhytmicity. ${ }^{10,25}$ Moreover, it also reduces the excitability of cardiac parasympathetic nerves in CNS. Though cardiac autonomic impairment results in excess mortality, only a few studies have assessed the autonomic nerve function status in hyperthyroidism. ${ }^{26}$

Several researchers have explored the cardiac autonomic nervous activity in hyperthyroid patients. It has been reported that sympathoadrenal axis is changed in these groups of patients. Again, some researchers reported exaggerated sympathetic efferent outflow in hyperthyroids. ${ }^{7,20,27,28}$

Heart rate variability is the result of cardiac autonomic nervous modulation on intrinsic cardiac automaticity. HRV analysis is used to detect the magnitude of the individual components of the autonomic control of the heart. Analysis of the R-R interval variation is used to assess the cardiac parasympathetic activity in healthy adults. ${ }^{29}$

Lower R-R interval variability and higher heart rate in untreated hyperthyroid patients but lower heart rate in hyperthyroids after treatment has been reported by many researchers $3,5,28,30$ Researchers investigating HRV in hyperthyroids found lower SDNN and RMSSD in untreated hyperthyroids. ${ }^{7,26,31}$

Hyperthyroidism is one of the common endocrine disorders in Bangladesh. Different cardiovascular and metabolic disorders may be associated with hyperthyroidism. Though most of them remain unnoticed, it is possible to prevent the development of such complications. Several studies on cardiac autonomic nerve dysfunction in diabetes mellitus ${ }^{32}$, renal failure ${ }^{33}$, aging ${ }^{34}$, obesity $^{35}$ and post-menopausal women ${ }^{36}$ were conducted by conventional method but no such

J Bangladesh Soc Physiol. 2009 Dec;4(2): 51-57 data on hyperthyroidism by analysis of HRV is yet available in our country.

Therefore, this study was carried out to assess the autonomic nerve function status in hyperthyroid patients. It is expected that the outcome of this study may be useful in screening of autonomic nerve function disorder in hyperthyroidism so that early treatment can be done to minimize risk of its complications.

\section{Methods}

This cross sectional study was carried out to observe the HRV by time domain method in 60 hyperthyroid patients with age ranged from 3050 years in the Department of Physiology, Bangabandhu Sheikh Mujib Medical University from $1^{\text {st } J u l y ~} 2007$ to $30^{\text {th }}$ June 2008. Hyperthyroid patients were divided into $\mathrm{B}_{1}$, untreated patients on their $1^{\text {st }}$ day of diagnosis and $B_{2}$, patients treated for at least 2 months. For comparison, 20 age and sex matched apparently healthy euthyroid subjects (group A) were also studied. The study group was selected from the Out Patient Department of Endocrinology, BSMMU, Dhaka. All the subjects were free from heart diseases, hypertension, diabetes mellitus, renal diseases, psychiatric disorders, hyperthyroidism due to exogenous L-thyroxine, pregnancy and smoking.

After selection, the subject was thoroughly informed about the aims, objectives and detail procedure of the study before examination and collection of blood sample. He or she was encouraged for voluntary participation and was allowed freedom to withdraw from the study whenever he / she liked even after participation. If he or she agreed to enroll to the study, informed written consent was taken from him / her. Then the subject was prepared for the study by giving advice to have their meal by 9:00 pm, free from any physical or mental stress, not to take sedatives or any drugs affecting central nervous 
Article

system and had a good sleep at night before the day of examination. He or she was advised to avoid tea or coffee at breakfast and was asked to attend the Department of Physiology of Bangabandhu Sheikh Mujib Medical University between 9:00 a.m. to11:00 a.m. on the day of examination. Then the subject was taken to Autonomic Nerve Function Test Laboratory and detail history was taken. Then his / her thorough physical examinations were done and all informations were recorded in a prefixed questionnaire. Then he / she was kept under complete bed rest in supine position for 15-20 minutes in a cool and calm environment. During this period the subject was advised not to talk, eat or drink and also not to perform any physical or mental activity, even sleep. Then all preparations for recording of the Heart Rate Variability parameters were made by connecting the channels of ECG and Pulse to a polygraph for 5 minutes(short term) ${ }^{27}$. After recording of HRV parameters, $5 \mathrm{ml}$ of venous blood was drawn from the subject. Serum TSH and serum $\mathrm{FT}_{4}$ levels were measured by AxSYM system. Heart Rate Variability parameters in time domain method like mean R-R interval, mean Heart Rate, SDNN (standard deviation of N-N interval) and RMSSD (square root of mean squared difference of successive NN intervals) were collected from Polygraphic recording. Data were expressed as mean and median. For statistical analysis MannWhitney U test was used.

\section{Results}

Anthropometric details of the subjects are presented in table I. Groups were matched for age, sex and height. The median body weight and BMI were significantly $(\mathrm{p}<0.001)$ lower in group $\mathrm{B}_{1}$ compared to those of group $\mathrm{A}$ and $B_{2}$. But no significant differences of these values were observed between group $\mathrm{A}$ and group $\mathrm{B}_{2}$.
HRV in Hyperthyroids

Table I: Anthropometric measures in different groups $(\mathrm{n}=80)$

\begin{tabular}{lcccc}
\hline Groups & $\begin{array}{c}\text { Age } \\
(\text { years })\end{array}$ & $\begin{array}{c}\text { Height } \\
(\mathrm{cm})\end{array}$ & $\begin{array}{c}\text { Weight } \\
(\mathrm{kg})\end{array}$ & $\begin{array}{c}\text { BMI } \\
\left(\mathrm{kg} / \mathrm{m}^{2}\right)\end{array}$ \\
\hline $\mathrm{A}$ & $38.5^{\mathrm{a}}$ & $160^{\mathrm{a}}$ & $53.5^{\mathrm{a}}$ & $20.87^{\mathrm{a}}$ \\
$(\mathrm{n}=20)$ & $39.15^{\mathrm{b}}$ & $160^{\mathrm{b}}$ & $54.1^{\mathrm{b}}$ & $21.00^{\mathrm{b}}$ \\
$\mathrm{B}_{1}$ & $35.5^{\mathrm{a}}$ & $157^{\mathrm{a}}$ & $43^{\mathrm{a}}$ & $17.77^{\mathrm{a}}$ \\
$(\mathrm{n}=30)$ & $38.87^{\mathrm{b}}$ & $160^{\mathrm{b}}$ & $46.05^{\mathrm{b}}$ & $17.83^{\mathrm{b}}$ \\
$\mathrm{B}_{2}$ & $41^{\mathrm{a}}$ & $159^{\mathrm{a}}$ & $49.5^{\mathrm{a}}$ & $20.02^{\mathrm{a}}$ \\
$(\mathrm{n}=30)$ & $40.8^{\mathrm{b}}$ & $161^{\mathrm{b}}$ & $52.77^{\mathrm{b}}$ & $20.13^{\mathrm{b}}$ \\
\hline Statistical analysis & & & \\
\hline $\mathrm{Groups}^{\mathrm{P}}$ & P value & & & \\
\hline $\mathrm{A} \mathrm{vs}_{1}$ & $0.882^{\mathrm{ns}}$ & $0.904^{\mathrm{ns}}$ & $0.000^{* * *}$ & $0.000^{* * *}$ \\
$\mathrm{~A}^{\mathrm{A}} \mathrm{B}_{2}$ & $0.366^{\mathrm{ns}}$ & $0.448^{\mathrm{ns}}$ & $0.475^{\mathrm{ns}}$ & $0.212^{\mathrm{ns}}$ \\
$\mathrm{B}_{1}$ vs B $_{2}$ & $0.251^{\mathrm{ns}}$ & $0.478^{\mathrm{ns}}$ & $0.000^{* * *}$ & $0.000^{* * *}$ \\
\hline
\end{tabular}

Data were expressed as a median and ${ }^{\mathrm{b}}$ mean.

$* * *=\mathrm{p}<0.001$, ns $=\mathrm{p}>0.05$.

The median value of TSH was significantly $(\mathrm{p}<0.001)$ lower and $\mathrm{FT}_{4}$ was higher $\left.\mathrm{p}<0.001\right)$ in group $B_{1}$ and $B_{2}$ than those of group $A$. Again though $\mathrm{FT}_{4}$ was significantly lower $\mathrm{p}<0.001$ ) in group $\mathrm{B}_{2}$ than that of $\mathrm{B}_{1}$ but TSH levels were almost similar in both the groups. (Table II).

Table II: Serum TSH and $\mathrm{FT}_{4}$ level in different groups $(\mathrm{n}=80)$

\begin{tabular}{lcc}
\hline Groups & $\mathrm{TSH}(\mathrm{mIU} / \mathrm{L})$ & $\mathrm{FT}_{4}(\mathrm{pmol} / \mathrm{L})$ \\
\hline $\mathrm{A}(\mathrm{n}=20)$ & $3.11^{\mathrm{a}} 2.79^{\mathrm{b}}$ & $10.25^{\mathrm{a}} 10.81^{\mathrm{b}}$ \\
$\mathrm{B}_{1}(\mathrm{n}=30)$ & $0.01^{\mathrm{a}} 0.023^{\mathrm{b}}$ & $51.03^{\mathrm{a}} 51.35^{\mathrm{b}}$ \\
$\mathrm{B}_{2}(\mathrm{n}=30)$ & $0.01^{\mathrm{a}} 0.022^{\mathrm{b}}$ & $25.06^{\mathrm{a}} 30.39^{\mathrm{b}}$ \\
\hline \multicolumn{2}{l}{ Statistical analysis } \\
\hline Groups & P value \\
\hline A vs B & $0.000^{* * *}$ & $0.000^{* * *}$ \\
$\mathrm{~A}$ vs B & $0.000^{* * *}$ \\
$\mathrm{~B}_{1}$ vs B $_{2}$ & $0.000^{* * *}$ & $0.000^{* * *}$ \\
\hline
\end{tabular}

J Bangladesh Soc Physiol. 2009 Dec;4(2): 51-57 
Mean and median values of mean R-R interval and HR were significantly $(\mathrm{p}<0.001)$ lower in group $\mathrm{B}_{1}$ than those of group $\mathrm{A}$ and $\mathrm{B}_{2}$. But no statistically significant differences of these values were found between group $A$ and group $B_{2}$. The median SDNN and RMSSD were significantly lower in group $\mathrm{B}_{1}$ than those of group $\mathrm{A}(\mathrm{p}<0.001)$ and group $\mathrm{B}_{2}(\mathrm{p}<0.01)$. However, no statistical significant differences of SDNN and RMSSD were observed between groups $A$ versus $B_{2}$.

Table III: Heart rate variability parameters in different groups $(\mathrm{n}=80)$

\begin{tabular}{lcc}
\hline Groups & $\begin{array}{c}\text { Mean R-R } \\
\text { interval (Sec) }\end{array}$ & $\begin{array}{c}\text { Mean H.R } \\
(\text { Beats/min) }\end{array}$ \\
\hline $\mathrm{A}(\mathrm{n}=20)$ & $0.74^{\mathrm{a}} 0.802^{\mathrm{b}}$ & $81.5^{\mathrm{a}} 76.7^{\mathrm{b}}$ \\
$\mathrm{B}_{1}(\mathrm{n}=30)$ & $0.57^{\mathrm{a}} 0.562^{\mathrm{b}}$ & $106^{\mathrm{a}} 106.7^{\mathrm{b}}$ \\
$\mathrm{B}_{2}(\mathrm{n}=30)$ & $0.74^{\mathrm{a}} 0.825^{\mathrm{b}}$ & $81^{\mathrm{a}} 75.5^{\mathrm{b}}$ \\
\hline Statistical analysis & \\
\hline Groups & $\mathrm{P}^{2}$ value & \\
\hline $\mathrm{A}_{\text {vs B }}$ & $0.000^{* * *}$ & $0.000^{* * *}$ \\
$\mathrm{~A}_{\text {vs B }}$ & $0.464^{\mathrm{ns}}$ & $0.571^{\mathrm{ns}}$ \\
$\mathrm{B}_{1}$ vs B $_{2}$ & $0.000^{* * *}$ & $0.000^{* * *}$ \\
\hline
\end{tabular}

Data were expressed as ${ }^{\mathrm{a}}$ median and ${ }^{\mathrm{b}}$ mean.

$* * *=\mathrm{p}<0.001, \mathrm{~ns}=\mathrm{p}>0.05$.

Table IV: Heart rate variability parameters (short term) in different groups $(n=80)$

\begin{tabular}{lcc}
\hline Groups & SDNN(ms) & RMSSD(ms) \\
\hline $\mathrm{A}(\mathrm{n}=20)$ & $32.42^{\mathrm{a}} 37.63^{\mathrm{b}}$ & $37.62^{\mathrm{a}} 49.14^{\mathrm{b}}$ \\
$\mathrm{B}_{1}(\mathrm{n}=30)$ & $13.62^{\mathrm{a}} 16.06^{\mathrm{b}}$ & $9.81^{\mathrm{a}} 16.06^{\mathrm{b}}$ \\
$\mathrm{B}_{2}(\mathrm{n}=30)$ & $20.91^{\mathrm{a}} 33.25^{\mathrm{b}}$ & $17.76^{\mathrm{a}} 38.29^{\mathrm{b}}$ \\
\hline
\end{tabular}

\begin{tabular}{|c|c|c|}
\hline \multicolumn{3}{|c|}{ Statistical analysis } \\
\hline Groups & P value & \\
\hline $\mathrm{A}_{\mathrm{vs}} \mathrm{B}_{1}$ & $0.000 * * *$ & $0.000 * * *$ \\
\hline A vs $B_{2}$ & $0.223^{\mathrm{ns}}$ & $0.216^{\mathrm{ns}}$ \\
\hline $\mathrm{B}_{1}$ vs $\mathrm{B}_{2}$ & $0.004^{* *}$ & $0.004 * *$ \\
\hline
\end{tabular}

Data were expressed as ${ }^{\mathrm{a}}$ median and ${ }^{\mathrm{b}}$ mean. $* * *=\mathrm{p}<0.001, \mathrm{~ns}=\mathrm{p}>0.05$.

J Bangladesh Soc Physiol. 2009 Dec;4(2): 51-57

\section{Discussion}

In the present study, heart rate variability (HRV) like mean R-R interval, mean heart rate, SDNN, RMSSD were measured by time domain method to assess cardiac autonomic nervous activity in patients with hyperthyroidism. Serum TSH and $\mathrm{FT}_{4}$ levels were also measured to determine their thyroid hormone status. All these parameters were compared with healthy age and sex matched adults. The autonomic nerve function status assessed by these HRV parameters in healthy subjects were almost similar to the findings reported by the investigators from different countries. ${ }^{5-7,20,31,37}$

In this study, all subjects were matched for age and sex. Serum TSH level was significantly lower and $\mathrm{FT}_{4}$ was significantly higher in both untreated and treated hyperthyroid patients compared to healthy control. The BMI was found significantly lower in untreated hyperthyroids in comparison to both healthy control and treated hyperthyroids. All these changes were due to the disease process involved

Significantly lower mean R-R interval and higher HR were found in untreated hyperthyroids compared to those of healthy and treated hyperthyroids. However, statistically no significant differences of these values were observed between treated hyperthyroids and healthy control. Similar findings were also observed by several investigators from different countries. ${ }^{4-7,10,15,20,28,30,31}$ The values of SDNN and RMSSD were found significantly lower in untreated hyperthyroids compared to those of both healthy control and treated hyperthyroid patients. But statistically no significant differences of these values were observed between healthy euthyroids and treated hyperthyroids. 7,26,31,37

It has been suggested that lower values of SDNN and RMSSD denote decreased high frequency component of HRV which is suggestive of decreased cardiac vagal modulation ${ }^{38}$. 
It has been suggested that reduced cardiac vagal effects in hyperthyroidism may be attributed to interference of peripheral neuroeffector mechanism and central inhibition of cardiac baroreflex reducing vagal discharge. ${ }^{30}$ Though, some studies ${ }^{39}$ observed the presence of increased sympathetic tone in hyperthyroidism but others ${ }^{6}$ found the normal levels of catecholamine or even reduced in hyperthyroidism.

Along with the CNS manifestations, excess thyroid hormones usually affect every single cell of human body and results in exaggerated manifestations as hyperadrenergic state and all of which have impact on heart rate. Thyroid hormones also cause increased intrinsic activity of SA node. ${ }^{21}$ In addition, these hormones potentiate the metabolic activity, oxygen consumption in peripheral tissue and beta receptors activities. ${ }^{15}$

Many researchers have observed R-R interval, heart rate, SDNN, RMSSD in hyperthyroids and found cardiac autonomic dysfunction in them. ${ }^{5,7,20}$ In the present study, hyperthyroid patients are most likely to be suffered from cardiac autonomic dysfunction as there are signs of decreased HRV indicated by lower values of mean R-R interval, mean Heart Rate, SDNN and RMSSD. More marked changes of all these values in untreated hyperthyroids than treated hyperthyroids also are in support of these findings. On the other hand, improvement of cardiac autonomic nerve function state in treated hyperthyroids in this study suggests that treatment may improve this dysfunctional state.

However, the exact mechanisms involved for the impairment of cardiac autonomic nervous activity in hyperthyroids can not be elucidated from this type of study. Assessment of serum or urinary catecholamines levels may be helpful to establish the involvement of neuroeffector mechanisms both centrally and peripherally in the hyperthyroid patients of the present series.

\section{Conclusion}

Cardiac autonomic nerve dysfunction may occur in hyperthyroid patients and proper treatment of the patients may improve the condition.

\section{Author affiliations}

*1. Md. Rasel Kabir, Assistant professor, Department of Physiology, ZH SikderWomen Medical College, Dhaka. Email:raselkabir623@gmail.com

2. Noorzahan Begum, Professor Department of Physiology, Bangabandhu Sheikh Mujib Medical University (BSMMU), Bangladesh. Email: noorzahanbeg@yahoo.com

3. Sultana Ferdousi, Assistant Professor, Department of Physiology, Bangabandhu Sheikh Mujib Medical University (BSMMU), Bangladesh. Email: sferdousiratna@gmail.com

5. Sultana Ferdousi, Assistant Professor, Department of Physiology, Bangabandhu Sheikh Mujib Medical University (BSMMU), Bangladesh. Email: sferdousiratna@gmail.com

6. Afroza Begum, Assistant Professor,(cc) Department of Community Medicine, Shahid Sohrawardy Medical college, Dhaka

\section{References}

1. Foley CM, Mc Allister RM, Hasser EM. Thyroid status influences baroreflex function and autonomic contributions to arterial pressure and heart rate. Am J Physiol Heart Circ Physiol. 2001; 280: H2061H2068.

2. Bhat AN, Kalsotra L, Yograj S. Autonomic Reactivity with Altered Thyroid Status. JK SCIENCE. 2007; 9(2): 70-74.

3. Maciel BC, Gallo LJr, Marin NJA, Maciel LM, Alves ML, Paccola GM, Iazigi N. The role of autonomic nervous system in the resting tachycardia of human hyperthyroidism. Clin Sci. 1987; 72: 239-244.

4. Inukai T, Kobayashi I, Kobayashi T, Ishii A, Yamaguchi T, Yamaguchi Y, Washita A, Shimomura Y, Kobayashi S. Parasympathetic nervous system in patients with Graves' disease determined by R-R interval variations on electrocardiogram. Exp Clin Endocrinol. 1990; 96(3): 289-295.

5. Cacciatori V, Bellavere F, Pezzarossa A, Dellera A, Gemma ML, Thomaseth K, Castello R, Moghetti T, Muggeo M. Power spectral Analysis of Heart Rate in Hyperthyroidism. $J$ Clin Endocrinol Metab. 1996; 81: 2828-2835.

6. Inukai T, Takanashi K, Kobayashi H, Fujiwara Y, Tayama K, Aso Y, Takemura Y. Power spectral analysis of variations in heart rate in patients with hyperthyroidism or hypothyroidism. Horm Metab Res. 1998; 30: 531-535.

J Bangladesh Soc Physiol. 2009 Dec;4(2): 51-57 
7. Burggraaf J, Tulen JHM, Lalezari S, Schoemaker RC, De Meyer PHEM, Meinders AE, Cohen AF, Pijl H. Sympatho-vagal imbalance in hyperthyroidism. Am J Physiol Endocrinol Metab. 2001; 281:E190-E195.

8. Levey GS, Klein I. Catecholamine-thyroid hormone interactions and the cardiovascular manifestations of hyperthyroidism. Am J Med. 1990; 88(6): 642-646.

9. Cairoli VJ and Crout JR. Role of the autonomic nervous system in the resting tachycardia of experimental hyperthyroidism. J Pharmacol Exp Ther. 1967; 158(1): 55-65.

10. Valcavi R, Menozzi C, Roti E, Zini M, Lolli G, Roti S, Guiducci U, Portioli I. Sinus Node Function in Hyperthyroid Patients. Clin Endocrinol Metab. 1992; 75: 239-242.

11. Maitland M, Frishman WH. Thyroid Hormone and Cardiovascular Disease. Am Heart J. 1998; 135(2): 187-196.

12. Woeber KA. Thyrotoxicosis and the Heart. $N$ Engl J Med. 1992; 327(2): 94-98.

13. Ojamaa K, Balkman C, Klein I. Acute effects of triiodothyronine on arterial smooth muscle cells. Ann Thorac Surg. 1993; 56(1): S66-67.

14. Faber J, Wiinberg N, Schifter S, Mehlsen J. Haemodynamic Changes Following Treatment of Sub-clinical and Overt Hyperthyroidism. Euro $J$ Endocrinol. 2001; 145: 391-395.

15. Klein I, Ojamaa K. Thyroid Hormone and the Cardiovascular System. N Engl J Med. 2001; 344(7): 501-509.

16. Coulombe P, Dussault JH, Letarte J, Simmard SJ. Catecholamine metabolism in thyroid diseases.I. Epinephrine secretion rate in hyperthyroidism and hypothyroidism. J Clin Endocrinol Metab. 1976; 42: $125-131$.

17. Coulombe P, Dussault JH, Walker P. Catecholamine metabolism in thyroid diseases.II. Norepinephrine secretion rate in hyperthyroidism and hypothyroidism. J Clin Endocrinol Metab. 1977; 44: 1185-1189.

18. Fagius J, Westermark K, Karlsson A. Baroreflexgoverned sympathetic outflow to muscle vasculature is increased in hypothyroidism. Clin Endocrinol. 1990; 33(2): 177-185.

19. Matsukawa T, Mano T, Gotoh E, Minamisawa K, Ishii M. Altered muscle sympathetic nerve activity in hyperthyroidism and hypothyroidism. $J$ Auton Nerv Syst. 1993; 42(2): 171-175.

20. Chen JL, Chiu HW, Tseng YJ, Chu WC. Hyperthyroidism is characterized by both increased sympathetic and decreased vagal modulation of heart rate: Evidence from spectral analysis of heart rate variability. Clin Endocrinol. 2006; 64(6): 611616.

21. Bilezikian JP, Loeb JN. The influence of hyperthyroidism and hypothyroidism on alpha and beta adrenergic receptor systems and adrenergic responsiveness. Endocr Rev. 1983; 4: 378-388.

22. Liggett SB, Shah SD, Cryer PE. Increased Fat and Skeletal Muscle â-Adrenergic Receptors but Unaltered Metabolic and Hemodynamic Sensitivity to Epinephrine in Vivo in Experimental Human Thyrotoxicosis. J Clin Invest. 1989; 83: 803-809.

23. Levine MA, Feldman AM, Robishaw JD, Ladenson PW, Ahn TG, Moroney JF, Smallwood PM. Influence of thyroid hormone status on expression of genes encoding $\mathrm{G}$ protein subunits in the rat heart. J Biol Chem. 1990; 265(6): 3553-3560.

24. Metz LD, Seidler FJ, McCook EC, Slotkin TA. Cardiac á-adrenergic receptor expression is regulated by thyroid hormone during a critical developmental period. J Mol Cell Cardiol. 1996; 28(5): 1033-1044.

25. Osman F, Gammage MD, Sheppard MC, Franklyn JA. Cardiac dysrhythmias and thyroid dysfunction: the hidden menace? J Clin Endocrinol Metab. 2002; 87(3): 963-967.

26. Osman F, Franklyn JA, Daykin J, Chowdhary S, Holder RL, Sheppard MC, Gammage MD. Heart Rate Variability and Turbulence in Hyperthyroidism Before, During, and After Treatment. Am J Cardiol. 2004; 94: 465-469.

27. Malliani A, Pagani M, Lombardi M, Cerutti S, Cardiovascular Neural regulation explored in the frequency domain. Circulation. 1991; 84(2): 482492.

28. Girard A, Hugues FC, Le-Jeunne C, Elghozi JL. Short term variability of blood pressure and heart rate in hyperthyroidism. Clin Auton Res. 1998; 8(3): 181186.

29. Ewing DJ, Neilson JMM, Travis P. New method for assessing cardiac parasympathetic activity using 24 hour electrocardiograms. Br Heart J. 1984; 52: 396-402. 


\section{Article}

HRV in Hyperthyroids

30. Kollai B, Kollai M. Reduced cardio vagal excitability in hyperthyroidism. Brain Res Bull. 1988; 20(6): 785-790.

31. Petretta M, Bonaduce D, Spinelli L, Vicario MLE, Nuzzo V, Marciano F, Camuso P, Sanctis VD, Lupoli G. Cardiovascular Hemodynamic and Cardiac Autonomic Control in Patients with Sub clinical and Overt Hyperthyroidism. Euro J Endocrinol. 2001; 145: 691-696.

32. Alam MK. Autonomic nerve function status in type2 DM: Relation to glycemic status, duration and ionized serum calcium and magnesium concentration [Thesis] [Dhaka (Bangladesh)]: BSMMU. 2004 July.

33. Rahman M. Assessments of some aspects of autonomic nerve function status in uremic patients with renal failure. [Thesis] [Dhaka (Bangladesh)]: BSMMU. 2005 July.

34. Islam T. Assessment of some aspects of autonomic nerve function status in healthy elderly subjects [Thesis] [Dhaka (Bangladesh)]: BSMMU. 2006 July.
35. Akhter S. Relationship between obesity and autonomic nerve function activity [Thesis] [Dhaka (Bangladesh)]: BSMMU. 2007 July.

36. Naher LAD. Study on some aspects of autonomic nerve function status and their relationships with serum estrogen and progesterone levels in postmenopausal woman [Thesis] [Dhaka (Bangladesh)]: BSMMU. 2008 Jan.

37. Perciaccante A, Fiorentini A, Paris A, Serra P, Tubani L. Circadian rhythm of autonomic nervous system in insulin resistance subjects with normoglycemia, impaired fasting glycemia, impaired glucose tolerance, type-2 diabetes mellitus. $B M C$ Cardiovasc Disord. 2006; 6.

38. Task Force of The European Society of Cardiology and The North American Society of Spacing and Electrophysiology. Heart Rate Variability: standards of measurement, physiological interpretation and clinical use.Circulation.1996; 93:1043-1065.

39. Christensen NJ. Plasma nor adrenalin and adrenalin in patients with Thyrotoxicosis and myxoedema. Clin.sci mol. Med. 1973;45:163-171. 